\title{
The Organizers' Goals
}

The wide range of disciplines represented by the participants and attendees of the Chemometrics Research Conference held at the Gaithersburg Holiday Inn on May 20-22, 1985, exemplifies the depth and diversity of the chemometrics community. The Conference was sponsored by several important professional societies whose members are involved in chemometric activity. These include the Analytical Division of the American Chemical Society, the Section on Physical and Engineering Sciences of the American Statistical Association, the Institute of Mathematical Statistics, and the Society for Applied Spectroscopy. Generous funding for the Conference was provided by the National Bureau of Standards, the Office of Naval Research, and the National Science Foundation.

As organizers, we had two main goals in mind when deciding on the form and substance of the Conference. The first was to provide a forum for reporting on some of the most recent and important research activities in diverse areas relating to chemometrics. Nineteen invited speakers covered topics including experimental design and optimization, kinetic rate constants, Kalman filtering, chromatography, data analysis, artificial intelligence, stochastic processes, regression and factor analysis. Despite the full schedule of papers, each of the five sessions was attended by nearly all of the 134 Conference registrants. Most of the papers are published in this special issue of the National Bureau of Standards Journal of Research to provide the registrants and others the opportunity for careful study of the presentations. In these respects, our first goal was easier to achieve than the second.

Our second and more important goal can only be achieved gradually. This was to increase the willingness of chemists, statisticians, and probabilists to meet as colleagues and to solve problems as a team. This will necessarily involve the exercise of communication skills as well as the combining of scientific skills. We believe that even the best separate efforts of chemists and mathematicians fall far short of the achievements that are possible by joint efforts in chemometric research teams. We underscored this aspect of teamwork between the disciplines of chemistry and mathematics by having each invited paper in one discipline discussed by an invited discussant of the other.

We invited the speakers to take any approach they desired in the exposition of their subject. Hence, the papers range from strictly technical to philosophical in tone. Discussants also had the option of either commenting on the specifics of a given paper, or exploring the relevance of the 
subject to their respective disciplines. This free format encouraged open discussion and exchange of ideas at the Conference, and we hope that the same stimulus will be provided by these Proceedings.

Finally, we look forward to future chemometrics conferences organized by researchers with perspectives other than our own. For no matter how broad the coverage of chemometrics topics in a given program, important areas are omitted. We believe that the widest scope of chemometrics research activities can be presented in meetings organized by committees of different backgrounds and insights.

Clifford H. Spiegelman

National Bureau of Standards

Robert L. Watters, Jr.

National Bureau of Standards

Jerome Sacks

University of Illinois, Urbana 